\title{
Surgical Outcome of Mandibular Swing Approach for Infratemporal Fossa Tumors
}

\author{
jitin Bajaj ${ }^{1}$ Arpan Mishra ${ }^{2}$ Anurag Pateriya ${ }^{1}$ Yadram Yadav $^{1} \quad$ Shailendra Ratre $^{1}$ Vijay Parihar $^{1}$ \\ ${ }^{1}$ Department of Neurosurgery, NSCB Medical College, Jabalpur, \\ Madhya Pradesh, India \\ 2 Department of General Surgery, NSCB Medical College, Jabalpur, \\ Madhya Pradesh, India \\ Address for correspondence Jitin Bajaj, MCh, Department of \\ Neurosurgery, NSCB Medical College, Jabalpur, Madhya Pradesh \\ 482003, India (e-mail: bajaj.jitin@gmail.com). \\ Indian J Neurosurg 2016;5:159-162.
}

\begin{abstract}
Introduction There are numerous approaches for infratemporal fossa tumors with their own pros and cons. Mandibular swing approach is simple and provides ample exposure. We describe 10 cases of these masses operated using this approach.

Materials and Methods It was a retrospective study in the authors' institute from 2011 to 2015. Data were recorded for demography, clinical features, presentation time lag, approach taken, extent of resection, histopathology, functional outcome, complications including nerve paresis, infection, any other morbidity and mortality, radiotherapy applied, and recurrence.

Results A total of 10 patients were operated. Average age of the patients was 33.5 years (standard deviation [SD], 9.33 years), and among the ten patients, six were female and four were male patients. Clinical features varied from cranial nerve paresis, facial swelling, trismus, and facial pain. Nine cases underwent primarily mandibular swing, out of which eight had complete resection of the mass. One other patient

Keywords

- mandibular swing approach

- infratemporal fossa tumors primarily underwent cervical approach with incomplete excision, and later the mandibular swing approach with complete excision of the tumor. Complications were transient with zero mortality.

Conclusion Mandibular swing approach, in a selected group of patients, is safe and able to provide total excision of infratemporal fossa masses with minimal morbidity.
\end{abstract}

\section{Introduction}

Infratemporal fossa masses are rare. The largest series is probably of Fisch describing his approaches in 51 patients. ${ }^{1}$ There are numerous approaches for these masses with their own pros and cons. For instance, Fisch type $C^{2}$ approach provides good exposure but is associated with permanent hearing loss. Preauricular transzygomatic, maxillary swing, ${ }^{3}$ and transantral ${ }^{4}$ approaches provide good exposure but are insufficient for parapharyngeal extension. Endoscopic approaches need a good understanding of the endoscopic anatomy, and are difficult. Mandibular swing provides good exposure with limitation for the intracranial extension. ${ }^{5} \mathrm{We}$

received

April 19, 2016

accepted

May 31, 2016

published online

November 22, 2016
DOI http://dx.doi.org/

$10.1055 / \mathrm{s}-0036-1588036$. ISSN 2277-954X. describe our experience of ten cases of these masses done with the mandibular swing approach.

\section{Materials and Methods}

This study was a retrospective review of the records of patients presenting with infratemporal fossa masses operated in our institute in a 5-year period from 2011 to 2015. Their age, sex, clinical features, time duration for presentation, approach taken, completeness of excision, post-op radiotherapy, and recurrence data were recorded. Mandibular swing approach was used to expose the tumor and resect it. Results were assessed in terms of extent of resection, functional outcome,

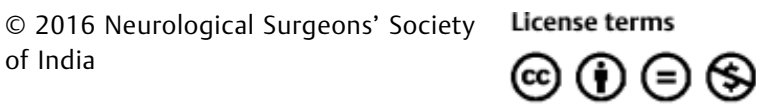




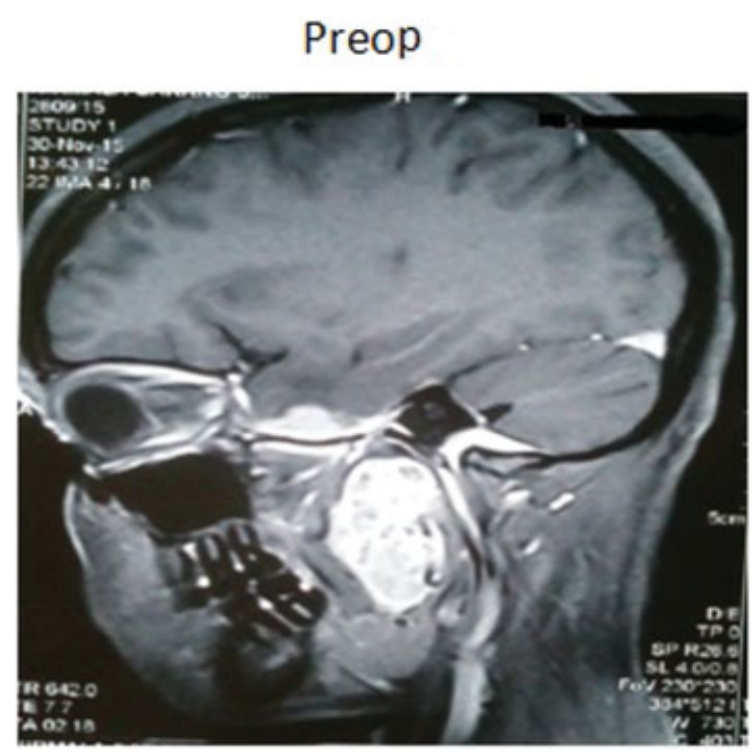

Fig. 1 Preoperative and postoperative images of the patient.

cosmetic outcome, and complications including new deficits. Extent of resection was assessed with the postoperative computed tomography (CT) or magnetic resonance imaging (MRI), the functional outcome with the resolution of complaints, cosmetic outcome using Likert scale with grading of excellent, good, fair, and poor, and complications with the occurrence of any new cranial nerve deficits, infection, or mortality.

All patients underwent $\mathrm{CT}$ and MRI of the face and brain (-Fig. 1). The operating team constituted an oncosurgeon, a neurosurgeon, and a plastic surgeon. Mandibular swing was the preferred approach.

Details of the procedure have been described elsewhere. ${ }^{6}$ The incision was made submandibular at the level of hyoid bone, with the medial limb coming up to the vermilion border of the lower lip in midline, and the lateral limb coming up to the angle of the mandible, as shown in - Fig. 2. Incision was extended into the floor of mouth in the paralingual gutter up to the anterior faucial pillar. After that, platysma was incised, and internal jugular vein and carotid artery were identified. Mandibulotomy was done at the level of the canine fossa, and then it was swinged laterally along with the pterygoid muscles. Tumor was then identified, dissected and taken out. Titanium plates were used for the reconstruction of the mandible and incision was closed in layers. Patients were followed-up on a trimonthly basis.

\section{Results}

It was a retrospective study done in the authors' institute by an experienced team. A total of ten cases were operated in this period and were followed-up. Mean age was 33.5 years (SD, 9.33 years) ranging from 22 to 50 years. There were four males and six females in the study. Patients presented with
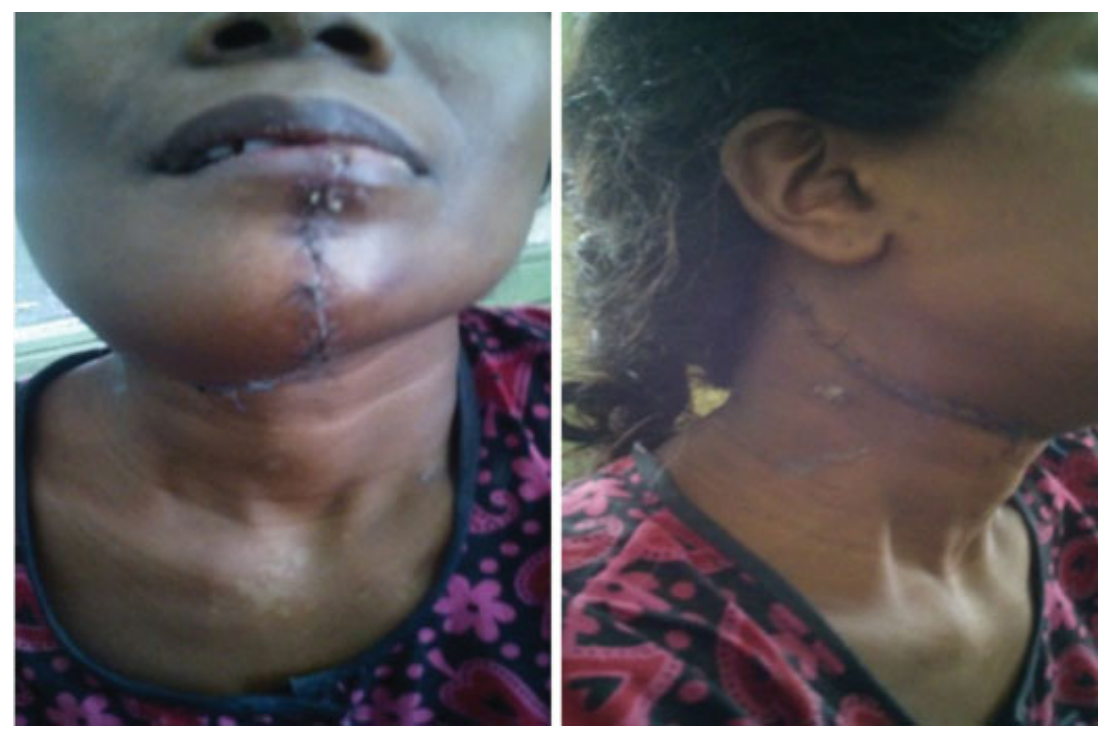

Fig. 2 Incision mark. 
symptoms of cheek swelling, neck swelling, cranial nerve (CN) V paresis, CN VII paresis, trismus, facial pain, etc, as shown in - Table 1. There were nine benign masses and one malignant mass in our study. Average duration of presentation was 2.9 years (SD, 0.69), ranging from 2 to 4 years. In nine patients, primarily mandibular swing approach was done, with complete removal of the mass in eight of them. In one patient, a portion of the tumor was invading the cavernous sinus which was left undisturbed. Another patient was initially operated using the cervical approach which resulted in incomplete removal of the mass leading to its recurrence, and was then followed by the mandibular swing approach resulting in complete excision of the mass. - Table 1 shows the age, sex, clinical features, time delay in presentation, approach taken, completeness of excision, histopathology, and recurrence data.

-Fig. 1 shows the preoperative and postoperative MRI of the mass in the patient with adenoid cystic carcinoma having perineural invasion up to the cavernous sinus. The portion in and around the cavernous sinus was left undisturbed. In six patients the tumor extended to parapharyngeal space (two prestyloid and four poststyloid) which were easily approached through the mandibular swing.

Postoperative complications were facial nerve paresis in two patients, hoarseness and drooping of shoulder in one patient, trismus in one patient, and odynophagia in two patients. All the complications were transient and resolved spontaneously. There was no case of infection, and there was no mortality in our series. All patients gave excellent grading on the Likert scale for cosmetic outcome. The average duration of the surgery was 3.1 hours, ranging from 2.5 to 4 hours. During the procedure, there was difficulty in reaching to the extension of the mass in temporal fossa and lateral wall of cavernous sinus.

One patient presenting with adenoid cystic carcinoma, which was invading the cavernous sinus, underwent radiotherapy and it resulted in resolution of the mass. There was no recurrence of the mass in this patient until 1 year of follow-up. Longest follow-up was 5 years and minimum followup was 1 year.

\section{Discussion}

Infratemporal fossa masses present a diverse group of pathologies constituting both benign and malignant ones. Because of their deep seating and indolent growth, these tumors have delayed presentation. These tumors, because of their proximity to both intracranial and extracranial structures, demand multispecialty team approach. In our institute, the team comprised of a neurosurgeon, an oncosurgeon, and a plastic reconstructive surgeon.

MRI and CT of the face and brain were performed in every case to identify the soft tissue and intracranial extension, along with CT angiogram in cases of parapharyngeal extension to rule out adherence to the neck vessels. Although, fine-needle aspiration cytology was not performed in any of our patient, but it can be used to identify the histology of the lesion, and can be taken through posterior to angle of mandible, transantral, or transoral route.

Table 1 Data showing age, sex, clinical presentation, presentation interval, extension to parapharyngeal space, approach used, histopathological report, completeness of excision, and recurrence of the infratemporal masses during the period 2011 to 2015

\begin{tabular}{|c|c|c|c|c|c|c|c|c|}
\hline S.no & Age/sex & Clinical features & $\begin{array}{l}\text { Presentation } \\
\text { interval }(y)\end{array}$ & $\begin{array}{l}\text { Extension to the } \\
\text { parapharyngeal } \\
\text { space }\end{array}$ & Approach & HPR & Excision & Recurrence \\
\hline 1 & $35 / F$ & $\begin{array}{l}\text { Cheek swelling, } \\
\text { V } 1,2,3 \text { paresis, VII paresis }\end{array}$ & 2 & Poststyloid & $\begin{array}{l}\text { Mandibular } \\
\text { swing }\end{array}$ & $\begin{array}{l}\text { Adenoid cystic } \\
\text { carcinoma }\end{array}$ & $\begin{array}{l}\text { Subtotal } \\
\text { excision }\end{array}$ & No \\
\hline 2 & $22 / \mathrm{F}$ & $\begin{array}{l}\text { Cheek swelling, } \\
\text { moderate hearing loss }\end{array}$ & 3 & Poststyloid & $\begin{array}{l}\text { Mandibular } \\
\text { swing }\end{array}$ & $\begin{array}{l}\text { Schwannoma } \\
\text { (IX nerve) }\end{array}$ & $\begin{array}{l}\text { Total } \\
\text { removal }\end{array}$ & No \\
\hline 3 & $25 / F$ & $\begin{array}{l}\text { Neck swelling, } \\
\text { hoarseness of voice }\end{array}$ & 2.5 & No & Cervical & Meningioma & $\begin{array}{l}\text { Subtotal } \\
\text { removal }\end{array}$ & $\begin{array}{l}\text { Yes, reoperated } \\
\text { with mandibular } \\
\text { swing, then } \\
\text { no recurrence }\end{array}$ \\
\hline 4 & $45 / \mathrm{M}$ & $\begin{array}{l}\text { Cheek swelling, heaviness } \\
\text { of head, nasal obstruction }\end{array}$ & 2 & Prestyloid & $\begin{array}{l}\text { Mandibular } \\
\text { swing }\end{array}$ & $\begin{array}{l}\text { Nasopharyngeal } \\
\text { fibroma }\end{array}$ & $\begin{array}{l}\text { Total } \\
\text { removal }\end{array}$ & No \\
\hline 5 & $40 / F$ & $\begin{array}{l}\text { Pain in cheek, } \\
\text { V1,2,3 paresis }\end{array}$ & 3 & Poststyloid & $\begin{array}{l}\text { Mandibular } \\
\text { swing }\end{array}$ & $\begin{array}{l}\text { Schwannoma } \\
\text { (VII nerve) }\end{array}$ & $\begin{array}{l}\text { Total } \\
\text { removal }\end{array}$ & No \\
\hline 6 & $50 / \mathrm{M}$ & Pain in cheek & 4 & Poststyloid & $\begin{array}{l}\text { Mandibular } \\
\text { swing }\end{array}$ & $\begin{array}{l}\text { Schwannoma } \\
\text { (VII nerve) }\end{array}$ & $\begin{array}{l}\text { Total } \\
\text { removal }\end{array}$ & No \\
\hline 7 & $26 / M$ & Cheek swelling, VII paresis & 3 & No & $\begin{array}{l}\text { Mandibular } \\
\text { swing }\end{array}$ & $\begin{array}{l}\text { Pleomorphic } \\
\text { adenoma }\end{array}$ & $\begin{array}{l}\text { Total } \\
\text { removal }\end{array}$ & No \\
\hline 8 & $30 / \mathrm{F}$ & $\begin{array}{l}\text { Cheek swelling, VII paresis, } \\
\text { numbness over face }\end{array}$ & 2.5 & No & $\begin{array}{l}\text { Mandibular } \\
\text { swing }\end{array}$ & $\begin{array}{l}\text { Pleomorphic } \\
\text { adenoma }\end{array}$ & $\begin{array}{l}\text { Total } \\
\text { removal }\end{array}$ & No \\
\hline 9 & $36 / F$ & Heaviness of head, trismus & 3 & No & $\begin{array}{l}\text { Mandibular } \\
\text { swing }\end{array}$ & Lipoma & $\begin{array}{l}\text { Total } \\
\text { removal }\end{array}$ & No \\
\hline 10 & $26 / \mathrm{M}$ & $\begin{array}{l}\text { Paresthesias over face, } \\
\text { trismus }\end{array}$ & 4 & Prestyloid & $\begin{array}{l}\text { Mandibular } \\
\text { swing }\end{array}$ & Meningioma & $\begin{array}{l}\text { Total } \\
\text { removal }\end{array}$ & No \\
\hline
\end{tabular}

Abbreviations: F, female; HPR, histopathology report; M, male. 
We chose mandibular swing approach for our patients as it was simple, provided ample exposure from cervical region to the skull base, and gave the option of proximal control of the blood vessels. In cases with tumor attached to mandible, segmental mandibulectomy can be performed, ${ }^{7}$ although we did not find the need of it in any of our patient. Radical excision was possible in all of our patients except in the patient who had the extension to the lateral wall of cavernous sinus (this is a limitation of this approach). Removing this part of the tumor is possible with combined approach that is, including preauricular transzygomatic approach. Few postoperative complications occur with the mandibular swing because of its good exposure; trismus, and nerve paresis generally improves spontaneously or with physiotherapy. Trismus occurs because of the swinging of pterygoid muscles along with the mandible, but because the muscle is not damaged the trismus resolves spontaneously. Postoperative nerve paresis was possibly because of neuropraxic injury which also resolved spontaneously.

Patients undergo radiotherapy for incomplete excision of the masses, whether the pathology is of adenoid cystic carcinoma or meningioma, ${ }^{7}$ and it was effective in resolution of the remaining portion of the mass attached to cavernous sinus in our patient.

Prognosis of these tumors depends upon the histology and totality of resection. Prognosis of the adenoid cystic carcinoma depends upon the tumor stage and presence of perineural and perivascular extension. There was recurrence of the mass in one of our patient because of the cervical approach, which could only remove the tumor partially, leading to redo surgery through the mandibular swing approach finally leading to its complete removal.

\section{Conclusion}

Mandibular swing approach, in selected group of patients, is safe and provides total excision of infratemporal fossa masses with minimal morbidity.

\section{Conflict of Interest}

None.

\section{Funding}

None.

Acknowledgments

None.

\section{References}

1 Fisch U. Infratemporal fossa approach to tumors of the temporal bone and base of the skull. J Laryngol Otol 1978;92(11):949-967

2 Fisch U, Fagan P, Valavanis A. The infratemporal fossa approach for the lateral skull base. Otolaryngol Clin North Am 1984;17(3):513-552

3 Wei WI, Lam KH, Sham JS. New approach to the nasopharynx: the maxillary swing approach. Head Neck 1991;13(3):200-207

4 Sewall EC. An operation for the removal of the sphenopalatine ganglion. Ann Otol Rhinol Laryngol 1926;79:967-969

5 Taylor RJ, Patel MR, Wheless SA, et al. Endoscopic endonasal approaches to infratemporal fossa tumors: a classification system and case series. Laryngoscope 2014;124(11):2443-2450

6 Ariel IM, Jerome AP, Pack GT. Treatment of tumors of the parotid salivary gland. Surgery 1954;35(1):124-158

7 Tiwari R, Quak J, Egeler S, et al. Tumors of the infratemporal fossa. Skull Base Surg 2000;10(1):1-9 